Gut, 1984, 25, 1078-1084

\title{
Reversible male infertility due to sulphasalazine: studies in man and rat
}

\author{
C Ó'MORÁIN, P SMETHURST, CAROLINE J DORÉ, \\ AND A J LEVI
}

From the Departments of Gastroenterology and Division of Computing and Statistics, Northwick Park
Hospital and Clinical Research Centre, Harrow, Middlesex

SUMMARY Sulphasalazine treatment for inflammatory bowel disease in man causes oligospermia, reduced sperm motility and an increased proportion of abnormal forms. On withdrawal of sulphasalazine these effects are found to be reversible and 15 pregnancies occurred at a median of 2.5 months after stopping sulphasalazine therapy. Seminal plasma concentrations of acid phosphatase fructose and $\mathrm{PGE}_{2}$ as well as the hormone profiles of patients on sulphasalazine for three months were found to be within normal limits. Sulphasalazine fed to male Sprague Dawley rats caused a dose dependent and reversible infertility with a significant reduction in litter size. Rats fed the metabolite sulphapyridine also had a reduced litter size when mated, while those fed the metabolite 5'aminosalicylic acid and a polymer of 5'aminosalicylic acid did not. It seems likely that the sulphapyridine moiety of sulphasalazine is responsible for the infertility seen, the effect being mediated at a late stage in sperm maturation.

Sulphasalazine has an established role in the treatment of ulcerative colitis and is increasingly used for indefinite maintenance treatment since its introduction over 40 years ago. ${ }^{1}$ It has also been used with some success in Crohn's disease particularly when the disease involves the colon. Male infertility was not a recognised complication ${ }^{2}$ until Levi and his colleagues ${ }^{3}$ published a report on four patients. Simultaneously and independently Toth $^{4}$ described a similar phenomenon, a characteristic 'megalo' head type sperm found in patients treated with sulphasalazine. Male infertility is now accepted as a frequent complication of sulphasalazine therapy. ${ }^{5-9}$

The aim of this study was to extend the original observations, and develop an animal model to study possible mechanisms.

\section{Methods}

MAN

Sixty four patients (ages 19-41 years) with inflammatory bowel disease documented by clinical histological or radiological means were able to provide

Address for correspondence: Dr A J Levi, Northwick Park Hospital and Clinical Research Centre, Harrow, Middlesex HA1 3UJ.

Received for publication 4 January 1984 semen samples. Informed consent was obtained. Semen was collected after at least 48 hours abstinence from seminal emission. All samples were analysed within two hours of production.

The patients were divided into three groups: Group 1: nine patients who were on no treatment. Group 2: 39 patients who were taken 2-4 g sulphasalazine for more than three months. Group 3: 16 patients who had discontinued sulphasalazine treament for more than three months.

Seminal plasma from eight patients on and off sulphasalazine for more than three months was analysed for acid phosphatase and fructose by a colorimetric method. ${ }^{10}{ }^{11} \mathrm{PGE}_{2}$ was analysed using gas chromatography. ${ }^{12}$

\section{Acetylator status}

The acetylator phenotypes of 20 patients on sulphasalazine therapy for at least three months were determined by Schröder's method with analyses performed in triplicate. ${ }^{13}$ Fast and slow acetylator phenotype groups were then compared with each other with respect to sperm count motility, and morphology.

\section{Hormone studies}

A modified gonadotrophin releasing hormone (gonadorelin, Gn RH) test was performed on eight 
patients while on and off sulphasalazine for longer than three months. The test consisted of forearm vein cannulation and the drawing of venous blood samples for leutinising hormone, follicle stimulating hormone, testosterone, at $-20,0,+20,+60$ minutes, prolactin at 0 and 20 minutes and 5 'alphadihydrotestosterone at 0 and 60 minutes.

One hundred micrograms of gonadorelin (HRF Ayerst) were injected intravenously immediately after withdrawing the 0 time samples. All samples were collected in heparin tubes. Samples were centrifuged and the plasma stored at $-20^{\circ} \mathrm{C}$ for subsequent radioimmunoassay. All analyses were carried out by the endocrine laboratory of the Chelsea Hospital for Women. Prolactin, and leutinising hormone were assayed by double antibody radioimmunoassay methods. Testosterone was by the method of Collins et al ${ }^{14}$ and 5'alphadihydrotestosterone assay by the method of Mansfield et al. ${ }^{15}$

\section{RATS}

Sulphasalazine dose response

Male Sprague Dawley rats, assigned at random to groups of size 10 , were treated with sulphasalazine at $0,154,386,617 \mathrm{mg} / \mathrm{kg}$ body $\mathrm{wt} /$ day for a period of eight weeks in addition to a normal diet. Fertility was assessed by sequential introduction of two virgin females. Twenty days after the date of mating, females were killed and numbers of live foetuses and resorptions counted. The foetuses were also weighed.

\section{Metabolites}

Groups of 10 male Sprague Dawley rats were treated with sulphapyridine $(321 \mathrm{mg} / \mathrm{kg}$ body wt/ day), $5^{\prime}$ aminosalicylic acid $(296 \mathrm{mg} / \mathrm{kg}$ body wt/day), and a compound composed of two 5'aminosalicylic acid molecules bound together (Pharmacia) (296 $\mathrm{mg} / \mathrm{kg}$ body wt/day) for a period of five weeks.

Fertility was again assessed by sequentially introducing two virgin female rats which were subsequently killed at 20 days after mating and the number of live foetuses and resorptions counted.

\section{Time course}

Groups of 10 male Sprague Dawley rats were treated with 0 and $617 \mathrm{mg} / \mathrm{kg}$ body wt/day of sulphasalazine and two virgin female rats were mated sequentially with these males after 21 days and 35 days on the drug, and at 6-10 days, 10-14 days, and 14-18 days off the drug. Fertility was assessed as described above.

\section{Histology}

Eight male Sprague Dawley rats treated with sulphasalazine at $617 \mathrm{mg} / \mathrm{kg}$ body wt/day and eight controls were killed at 10 weeks. Their testes, epididymis and ventral prostate were weighed; and also examined histologically after fixation in haematoxylin and eosin.

\section{STATISTICAL ANALYSIS}

Mean values for the three patient groups were compared using analysis of variance, and contrasts were performed to compare each salazopyrine group with the control group. For comparisons involving two patient groups $t$ tests were used. Sperm count was square root transformed, while morphology and acid phosphatase were $\log _{10}$ transformed to achieve homogeneity of variance.

The mean litter size and mean number of resorptions were calculated for each male rat, and Kruskal-Wallis analysis of variance of ranks was used to compare treatment groups. Mann-Whitney $\mathrm{U}$ tests were performed to compare each treatment group with the control group.

\section{Results}

\section{MAN}

Group I patients who had documented inflammatory bowel disease and were receiving no treatment had mean sperm counts of 49.3 (95\% confidence limits for the mean $27 \cdot 7-77 \cdot 1)$ progressively motile sperm $48.6(34.4-62.7) \%$ and abnormal forms $21.7(15 \cdot 8-29.6) \%$ which was comparable with the normal limits in our lab. (Sperm density normal range is greater than or equal to $40 \times 10^{6} \mathrm{sperm} / \mathrm{ml}$, sperm motility normal range is greater than or equal to $60 \%$ and sperm morphology normal range is less than or equal to $30 \%$ abnormal forms) (Fig. 1).

Group II patients on sulphasalazine, $2-4 \mathrm{~g} /$ day had a significant decrease in sperm counts, 24.0 $(16.4-32.9) \times 10^{6} \mathrm{sperm} / \mathrm{ml}(\mathrm{p}=0.03)$ and motility $29.6(22.8-36.4) \%(\mathrm{p}=0.03)$ and an increase 35.3 $(30.5-40.9) \%(\mathrm{p}=0.008)$ in abnormal morphological forms (Fig. 1).

Group III patients had sperm counts of 55.7 $(37.7-77 \cdot 1) \times 10^{6}$ sperm $/ \mathrm{ml}$, motility $48.2(37.6-$ $58.8) \%$ and $22.9(18 \cdot 2-28 \cdot 8) \%$ abnormal forms and were not significantly different from the Group I patients (Fig. 1).

The period of ingestion before withdrawal was a mean of 4.5 years. All the patients were trying to father children. The median interval between withdrawal of sulphasalazine and pregnancy was 2.5 months. A single patient was off the drug for two years before successful fertilisation. Of 15 pregnancies, one resulted in a spontaneous abortion, 13 in full term normal delivery, and in one 

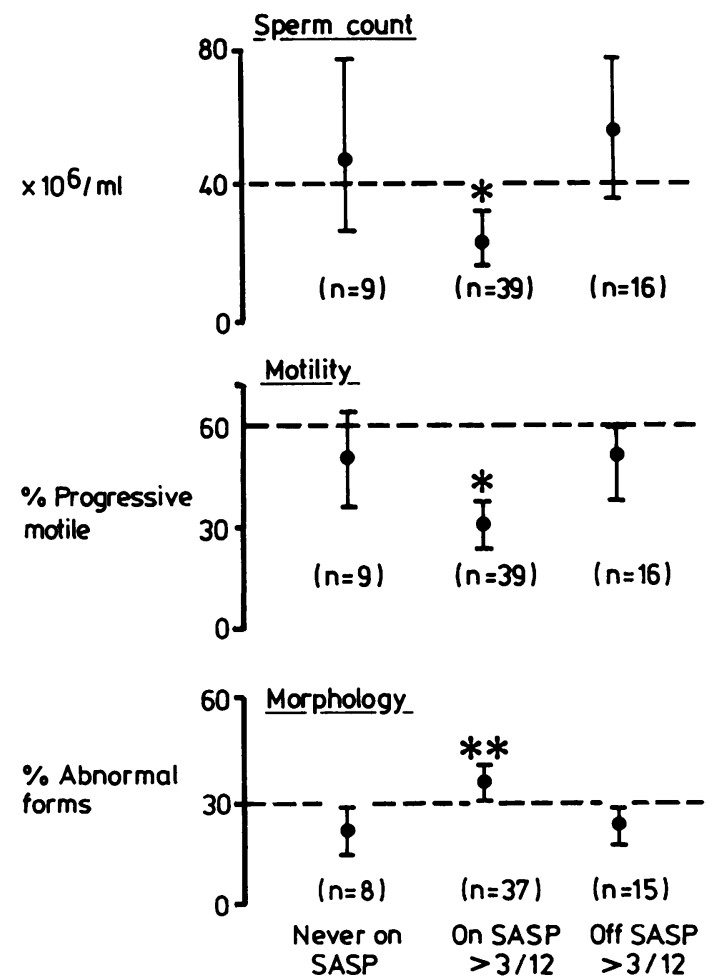

Fig. 1 Graph of mean and $95 \%$ confidence limits of sperm counts, motility and morphology of patients with inflammatory bowel disease before, on, and off sulphasalazine therapy. Dotted lines indicate accepted normal levels for male fertility. (Comparison with Group I never on sulphasalazine $\left.{ }^{*} p<0.05,{ }^{* *} p<0.01\right)$. SASP $=$ sulphasalazine.

the result is awaited.

Three of the patients in Group II fathered full term normal children while on sulphasalazine.

\section{Seminal plasma}

Semen acid phosphatase was 55560 (15 810$195300) \mathrm{IU} / \mathrm{l}$ while on sulphasalazine and 53860 (15 330-189 300) IU/1 when off sulphasalazine. Fructose was $17.0(9.9-24 \cdot 1) \mathrm{mmol} / \mathrm{l}$ while on sulphasalazine and $16 \cdot 1(9 \cdot 6-22 \cdot 7) \mathrm{mmol} / \mathrm{l}$ when off sulphasalazine. $\mathrm{PGE}_{2}$ was $44(19 \cdot 2-68 \cdot 8) \mu \mathrm{g} / \mathrm{ml}$ while on sulphasalazine and $46.5(14 \cdot 6-78.4) \mu \mathrm{g} / \mathrm{ml}$ when off sulphasalazine. In no case was there a significant difference when on and off drug (Fig. 2).

\section{Acetylator status}

The slow acetylator patients had significantly lower sperm counts than fast acetylators $6 \cdot 3(0 \cdot 1-21 \cdot 6) v s$ $41 \cdot 2(21 \cdot 9-66 \cdot 7) \times 10^{6} \mathrm{sperm} / \mathrm{ml}(\mathrm{p}=0 \cdot 008)$. Motility

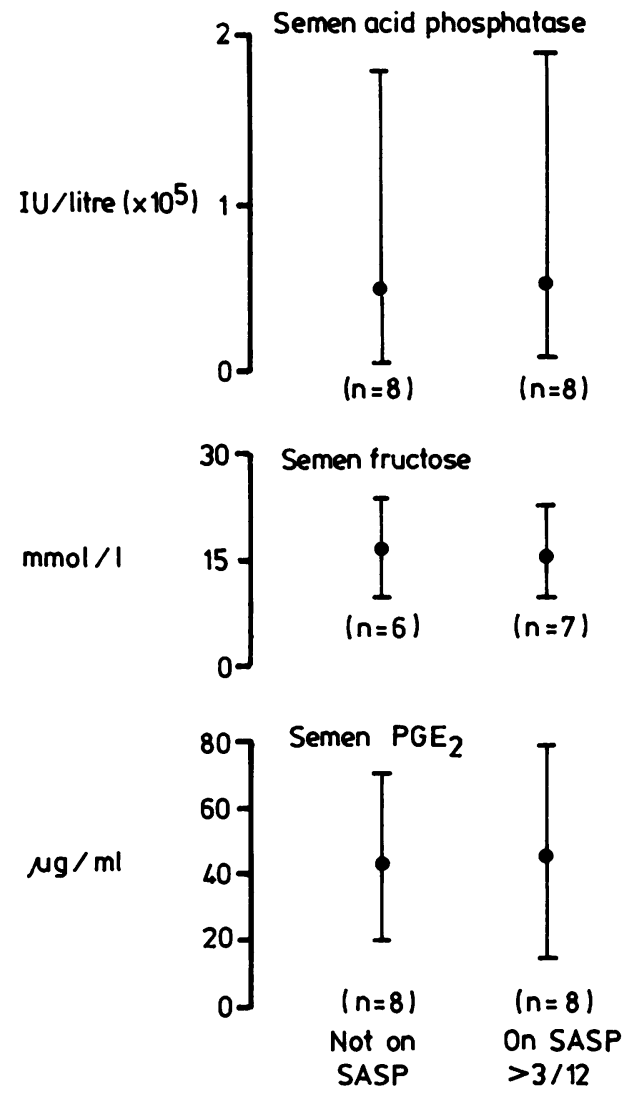

Fig. 2 Graph of mean and $95 \%$ confidence limits of seminal plasma acid phosphatase, fructose and $P G E_{2}$ of patients on and not on sulphasalazine therapy.

was decreased in slow compared with fast acetylators $28.8(10 \cdot 3-47.2)$ vs $39.3(24.2-54.3) \%$ progressive motile sperm while number of abnormal forms were increased in slow compared with fast acetylators $41.6(29.6-58.4)$ vs $32.2(24.8-41.7) \%$ abnormal. Neither motility nor morphology showed any significant differences between the two groups (Fig. 3).

\section{Hormones}

The hormone profiles both on and off treatment were virtually identical for $\mathrm{LH}, \mathrm{FSH}$, testosterone and prolactin (Fig. 4).

RATS

The drug treated animals gained weight and appeared as healthy as the controls.

No significant decrease in pregnancy rate was found with sulphasalazine $(80 \%)$ or its metabolites 


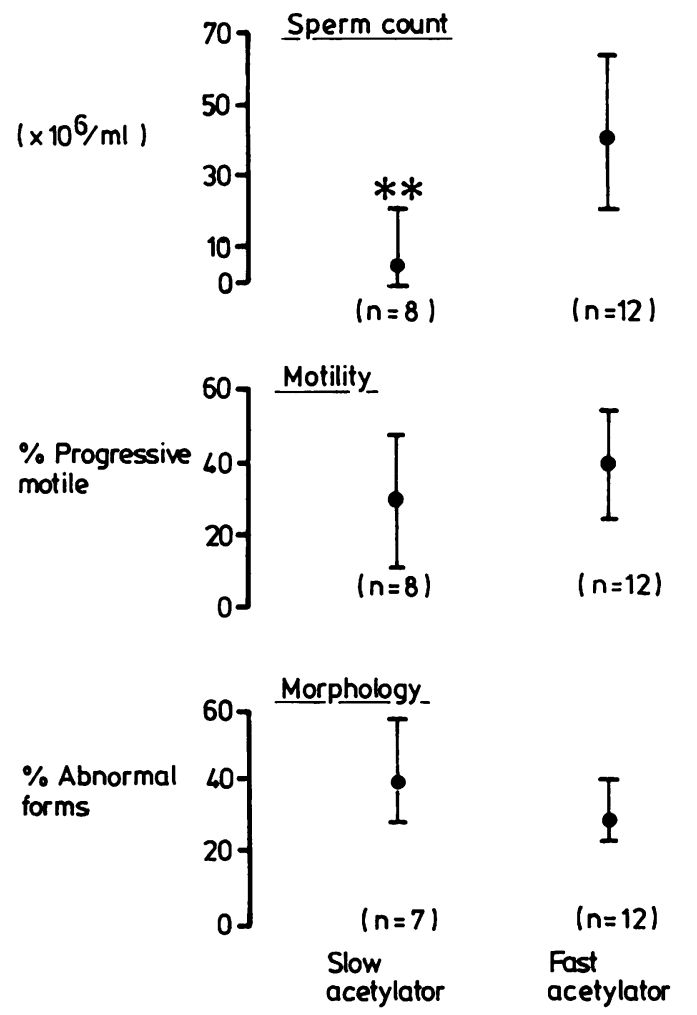

Fig. 3 Comparison of sperm counts, motility and percentage abnormal forms in fast and slow acetylator phenotypes on sulphasalazine therapy. (Mean and $95 \%$ confidence limits). (Comparing slow and fast acetylators $\left.{ }^{* *} p<0 \cdot 01\right)$.

sulphapyridine $(75 \%)$ and 5 'aminosalicylic acid $(80 \%)$ or the 5 'aminosalicylic acid-5'aminosalicylic acid polymer $(80 \%)$, compared to controls $(80 \%)$.

There was a dramatic reduction in median litter size in the groups treated with sulphasalazine for eight weeks $3.50(2.0-6.5)$ live/pregnant female (median and its $95 \%$ confidence limits) compared with controls $14 \cdot 0(12 \cdot 0-15 \cdot 50)$ live/pregnant female $(p=0 \cdot 0001)$. This was also seen when sulphapyridine was compared with controls $6 \cdot 0(2 \cdot 5-10 \cdot 5)$ vs 12.25 (11.5-13.0) live/pregnant female $(\mathrm{p}=0.0001)$, but not for 5 ' aminosalicylic acid compared with controls $13.75(8.0-17.0)$ vs $14.0(11.0-14.5)$ live/pregnant female, or with 5 'aminosalicylic acid bound to itself $13.0(12 \cdot 0-14.0)$ live/pregnant female compared with controls $13.0(10.5-14.0)$ live/pregnant female (Fig. 5).

The effect of sulphasalazine on litter size was dose related. The litter size after eight weeks drug
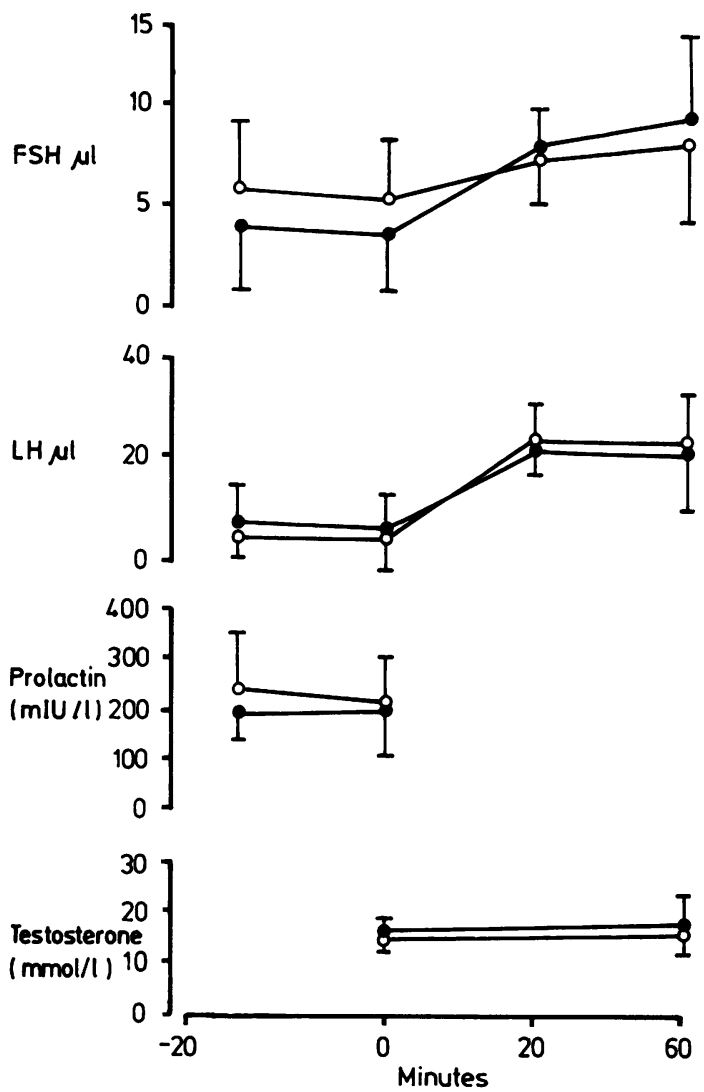

Fig. 4 Hormone profile of eight patients, while on and off sulphasalazine treatment after stimulation at 0 with 100 micrograms of gonadorelin. (Mean and $95 \%$ confidence limits).

treatment was $3.5(2 \cdot 0-6 \cdot 5)$ live/pregnant female at $617 \mathrm{mg} / \mathrm{kg}$ body wt/day; $4 \cdot 75(2 \cdot 0-7 \cdot 0)$ at $385 \mathrm{mg} / \mathrm{kg}$ body wt/day and $7 \cdot 0(2 \cdot 0-12 \cdot 5)$ at $154 \mathrm{mg} / \mathrm{kg}$ body wt/day compared with controls $14 \cdot 0(12 \cdot 0-15 \cdot 5)$ live/pregnant female (Fig. 6).

Foetal weights and numbers of resorptions were similar in all groups studied.

Time course

The time course experiments suggested that an effect was evident after two weeks exposure and that this effect was reversible, as the litter size of female rats mated with treated males had returned to normal at 14 days after drug withdrawal (Fig. 7).

\section{Histology (Table)}

There was little change in either the weight of testosterone accessory glands or the histological appearance of this tissue. 


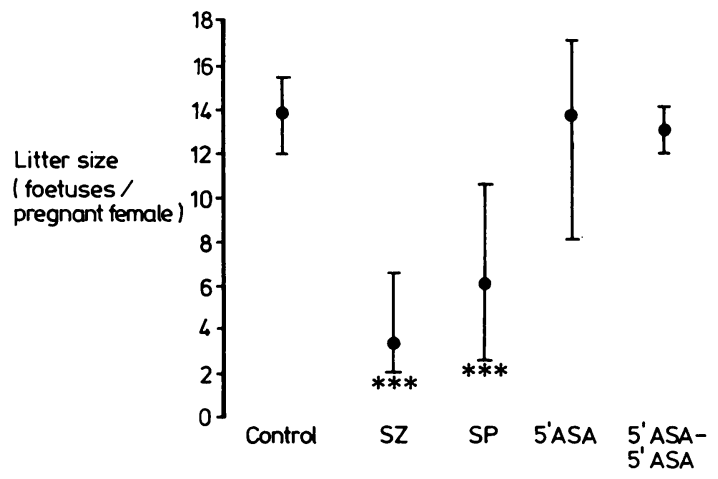

Fig. 5 Litter size for females mated with rats treated with sulphasalazine and its metabolites sulphapyridine,

5 'aminosalicylic acid and a polymer of 5'aminosalicylic acid for eight weeks and control. (Median and $95 \%$ confidence limits). (Comparison with control $* * * p<0.0001)$.

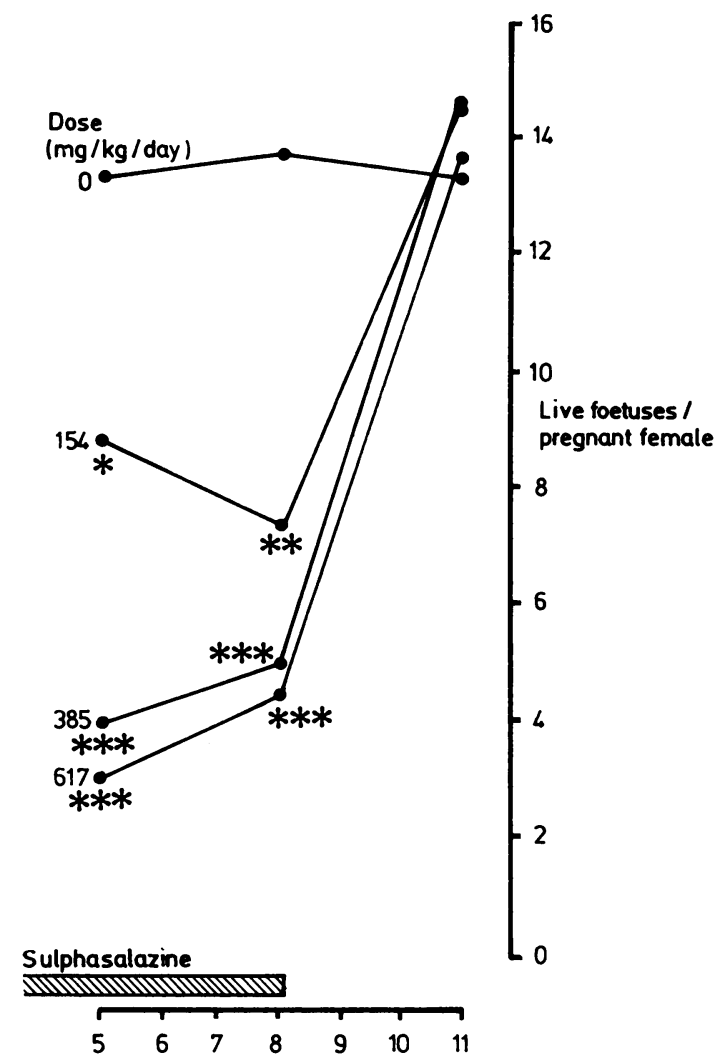

Fig. 6 Dose response of sulphasalazine on litter size at five and eight weeks and three weeks after withdrawal. (Comparison with control ${ }^{*} p<0.05,{ }^{* *} p<0.01$, $\left.{ }^{* * *} p<0.0001\right)$.

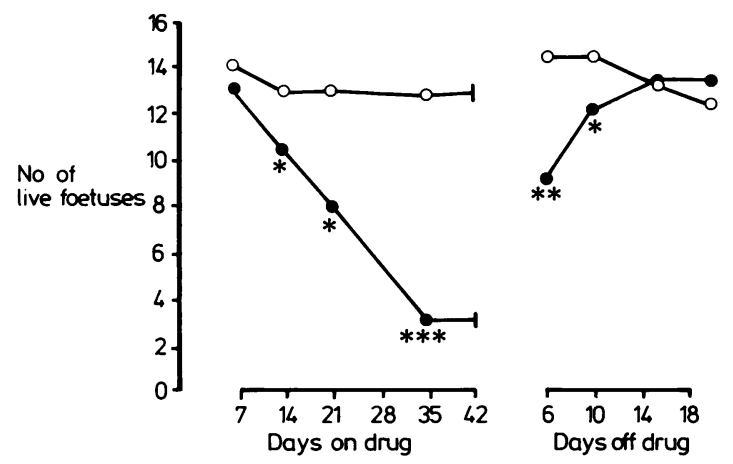

Fig. 7 Litter size after 7, 21, 35 days on and 6-10, 10-14, 14-18 days off sulphasalazine. (Comparison with control $\left.{ }^{*} p<0.05,{ }^{* *} p<0.01,{ }^{* * *} p<0.0001\right)$.

\section{Discussion}

These studies extend our previous observations that sulphasalazine has a spoiling effect on human semen. There is a significant fall in the sperm count, a decrease in motility and an increased number of abnormal forms. These abnormalities were reversed three months after drug withdrawal. Further evidence that this effect is reversible is provided by the 15 pregnancies which occurred after a median withdrawal time of 2.5 months.

Three patients apparently fathered children while on the drug. This emphasises that the laboratory measurements are not absolute indicators of fertility. The infertility was not caused by inflammatory bowel disease as patients not on treatment had normal semen measurements even though their symptoms wene often more severe than those of treated patients. This differs from Schramm et al ${ }^{16}$ who found that patients with inflammatory bowel disease had abnormal spermatograms although no information on drug therapy was given.

The effect appears not to be mediated hormonally as the patients had an almost identical hormone profile while on and off the drug. The seminal plasma measurements were all within normal limits.

Sulphasalazine and its metabolite sulphapyridine induces a reversible infertility in male rats. The time course investigation showed that recovery occurs within 14 days of withdrawal. The maturation of sperm from spermatogonia is 60 days in rats. ${ }^{17}$ This would suggest the effect is on sperm maturation. Further evidence for this is that testes weight and histology showed no changes. Sulphasalazine has been shown to be an inhibitor of intestinal folate transport ${ }^{18}$ and has the properties of an antifolate drug as it inhibits the enzyme dehydrofolate 
Table Mean weight (mean and $95 \%$ confidence limits) of testes and accessory organs in control rats treated with sulphasalazine ( $617 \mathrm{~kg} / \mathrm{kg}$ body weight) for eight weeks. Eight rats in each group.

\begin{tabular}{lll}
\hline & \multicolumn{2}{l}{ Weight $(g)$} \\
\cline { 2 - 3 } & Controls & Treated \\
\hline Testes & $1.93(1 \cdot 68-2 \cdot 17)$ & $1 \cdot 88(1 \cdot 64-2 \cdot 12)$ \\
Seminal vesicles & $0 \cdot 6(0 \cdot 36-0 \cdot 84)$ & $0 \cdot 7(0 \cdot 46-0.94)$ \\
Ventral prostate & $0.9(0 \cdot 66-1 \cdot 14)$ & $0 \cdot 7(0 \cdot 46-0.94)$ \\
\hline
\end{tabular}

reductase, methenetetrahydrofolate reductase, and serine transhydromethylase. ${ }^{19}$

Sperm have to undergo a maturation process before they are able to fertilise an egg, and one of the major steps in this process is the acrosome reaction. The acrosome is a membrane bound organelle located in the sperm head and it contains many enzymes, at least some of which appear to play a specific role in the penetration of sperm through the layers surrounding the egg. During the acrosome reaction, the sperm plasma membrane and the outer acrosomal membrane fuse forming vesicles and thus permitting release of enzymes.

It is possible that sulphasalazine and sulphapyridine inhibit enzymes in the acrosomal membrane. The large head may merely reflect membrane damage because of the resulting leakage. ${ }^{4}$ It is interesting to note that patients on sulphasalazine have a characteristic 'megalo' head form which may be caused by the antifolate effect of sulphasalazine. ${ }^{20}$ Giving patients large doses of folate, however, failed to improve the sperm counts whereas withdrawal of sulphasalazine did improve them (unpublished data).

The rat studies showed that the semen spoiling effect of sulphasalazine was dose related. This would be in keeping with the finding of lower sperm counts in the slow acetylators who presumably had higher sulphasalazine blood levels.

It is possible that sulphasalazine or some part of the sulphapyridine molecule may have a future role as a male contraceptive. Gossypol ${ }^{21}$ and chlorinated sugars $^{22}$ have been found to induce low sperm counts. Both of these compounds are toxic. Gossypol has been used with success in China in man but is only recently available for evaluation in the West. Chlorinated sugars inhibit glycolytic enzymes in the sperm. Glucose is required for optimal results in the in vitro fertilisation of rat eggs. ${ }^{22}$ As it is the sulphapyridine moiety that causes this side effect and it is 5 'aminosalicylic acid which is the active therapeutic component, ${ }^{23}$ the recognition of this important side effect may hasten the use of new compounds of 5'aminosalicylic acid which we have shown not to induce infertility in the rat. It is surprising that it has taken 40 years to discover the side effect and emphasises the need to take a drug history from both partners when investigating infertility. It is important to advise patients as the peak onset of the disease is in the younger age group and current practice is to prescribe long term sulphasalazine therapy.

The authors are grateful to Dr R W Kelly, Medical Research Council Unit of Reproductive Biology, Edinburgh, for $\mathrm{PGE}_{2}$ results and Dr M Dawsett, Chelsea Hospital for Women, for the hormone results. Dr Ó'Moráin is now consultant gastroenterologist, Adelaide and Meath Hospitals, Dublin 8 , Eire.

\section{References}

1 Svartz N. Salazopyrine, a new sulfanilamide preparation. Acta Med Scand 1942; 110: 577-98.

2 Summers RW, Switz DM, Sessions JT et al. National Cooperative Crohn's Disease Study. Results of drug treatment. Gastroenterology 1979; 77: 827-8.

3 Levi AJ, Fisher AM, Hughes L, Hendry WF. Male infertility due to sulphasalazine. Lancet $1979 ; 2: 276-8$.

4 Toth A. Reversible toxic effect of salicylazosulfapyridine on semen quality. Fertil Steril 1979; 31: 538-40.

5 Toovey S, Hudson E, Hendry WF, Levi AJ. Sulphasalazine and male infertility reversibility and possible mechanism. Gut 1981; 22: 445-51.

6 Birnie GG, McLeod TI, Watkinson G. Incidence of sulphasalazine induced male infertility. Gut 1981; 22: 452-5.

7 Malchow H. Wirkungen Von Salazosulfapyridin Auf Die Fertilität. $Z$ Gastroenterol 1981; 19: suppl: 21-3.

8 Freeman JG, Reece VA, Venables CW. Sulphasalazine and spermatogenesis. Digestion 1982; 23: 68-71.

9 Heineman MJ, Dony JMJ, Rolland R. Salicylazosulfapyridine and male infertility. Eur J Obstet Gynecol Reprod Biol 1981; 12: 297-303.

10 Horstein $O$. Vergleichnde Untersuchungen Zum Fructose-und glucosegehalt des menschlichen spermaliquors. Arch Klin Exp Dermatol 1961; 212: $257-74$

11 Roy AV, Brower ME, Hayden JF. Sodium tymalphthalein monophospholate. A new acid phosphatase substrate with greater specificity for the prostatic enzymes in serum. Clin Chem 1981; 17: 1093-102.

12 Cooper I, Kelly RW. The measurement of E and 19 hydroxy $E$ prostaglandins in human seminal fluid. Prostaglandins 1975; 10: 507-14.

13 Schröder $\mathrm{H}$. Simplified method for determining the acetylator phenotype. Br Med J 1972; 3: 506-7.

14 Collins WP, Mansfield M, Allandria NS, Sommerville IF. Radioimmunoassay of plasma testosterone. $J$ 
Steroid Biochem 1972; 3: 333-48.

15 Mansfield MD, Johnson MN. The determination of testosterone and five related steroids in human plasma. Proceedings of the fourth international congress on human steroids, Mexico City. J Steroid Biochem 1973; 5: 305.

16 Schramm P, Ewe K, Karbach U. Spermiogrammuntersuchungen bei Morbus Crohn Patienten. Andrologia 1981; 13: 352-8.

17 Setchell BP. In the mammalian testes. St. Albans, Herts: Elek Books, 1978.

18 Franklin JL, Rosenberg IH. Impaired folic acid absorption in inflammatory bowel disease, effects of salicylazosulphapyridine. Gastroenterology 1973; 64: 517-25.
19 Selhub J, Dhar GJ, Rosenberg IH. Inhibition of folate enzymes by sulphasalazine. J Clin Invest 1978; 61: 221-4.

20 Hudson E, Doré C, Sowter C, Toovey S, Levi AJ. Sperm size in patients with inflammatory bowel disease on sulphasalazine therapy. Fertil Steril 1982; 38: 77-84.

21 National Coordinating group on male antifertility agent for males. Chim Med J (Engl) 1978; 4: 417-28.

22 Ford WCL, Harrison A. The effect of 6-chloro-6deoxysugars on enderine nucleotide concentrations and motility of rat spermatogon. J Reprod Fertil 1981; 63: 75-7.

23 Azad Khan AK, Pino J, Truelove SC. An experiment to determine the active therapeutic moiety of sulphasalazine. Lancet 1977; 2: 892-8. 